\title{
Knockdown of HOXA transcript at the distal tip suppresses the growth and invasion and induces apoptosis of oral tongue squamous carcinoma cells
}

This article was published in the following Dove Press journal:

OncoTargets and Therapy

Mingkui $\mathrm{Mu}^{\prime}$

Yue $\mathrm{Li}^{\prime}$

Yuanbo Zhan ${ }^{2}$

Xin $\mathrm{Li}^{3}$

Bin Zhang ${ }^{2,4}$

'Department of Orthodontics, The Second Affiliated Hospital of Harbin Medical University, Harbin I5008I,

People's Republic of China; ${ }^{2}$ Institute of Hard Tissue Development and Regeneration, The Second Affiliated Hospital of Harbin Medical University, Harbin I5008I, People's Republic of China; ${ }^{3}$ Department of Stomatology, The Fourth Affiliated Hospital of Harbin Medical University, Harbin I5000 I, People's Republic of China; ${ }^{4} \mathrm{Heilongjiang}$ Academy of Medical Sciences, Harbin I5000I, People's Republic of China
Correspondence: Bin Zhang Institute of Hard Tissue Development and Regeneration, The Second Affiliated Hospital of Harbin Medical University, 246 Xuefu Road, Harbin I5000I, People's Republic of China Tel +86 45। 8660 5I90 Email zhangbinyzz@।26.com
Background: Oral tongue squamous cell carcinoma (OTSCC) is an aggressive cancer which has high mortality rates. HOXA transcript at the distal tip (HOTTIP) is a lncRNA that can be used as a prognostic marker in multiple carcinomas. The expression of HOTTIP is found to be elevated in OTSCC tissues, and such elevation is correlated with poor prognosis. However, its functional role in regulating the growth and metastasis of OTSCC cells remains elusive and requires further investigation.

Methods: HOTTIP-silenced OTSCC cells were established by inhibiting HOTTIP expression via its exclusive shRNA. Whether HOTTIP knockdown affected the aggressive tumor behaviors of OTSCC cells was investigated in vitro and in vivo.

Results: We found that HOTTIP shRNA restrained the cell proliferation and arrested the cell cycle at G1 phase in TSCCA and TCA8113 cells. The expression levels of cyclins B, D1, and $\mathrm{E}$ were downregulated in HOTTIP-silenced cells. HOTTIP silencing suppressed the growth of xenograft tumors. Moreover, the silencing of HOTTIP triggered apoptosis in TSCCA and TCA8113 cells and altered the expression of a group of apoptosis-related molecules: downregulated Bcl-2, upregulated Bax, and enhanced the cleavage of caspase 3 and PARP. Knockdown of HOTTIP also suppressed the migration, invasion, and epithelial-mesenchymal transition (EMT) of both TSCCA and TCA8113 cell lines.

Conclusion: Our findings suggest that HOTTIP is required by the OTSCC cells to maintain their growth and metastasis in vitro. It may serve as a promising potential candidate for OTSCC therapy.

Keywords: HOTTIP, oral tongue squamous cell carcinoma, proliferation, metastasis, apoptosis, tumorigenicity

\section{Introduction}

Oral tongue squamous cell carcinoma (OTSCC) is one of the most common malignancies, which has an unfavorable prognosis. ${ }^{1}$ The incidence of OTSCC is high globally, especially in Asian countries. ${ }^{2}$ The morbidity and fatality rates of OTSCC are still high, although improvements have been made in the current treatments (surgery, chemotherapy, and radiotherapy). ${ }^{3}$ At the early stages of OTSCC, $20 \%$ of the patients die. The strongest pathological predictors for recurrence and mortality are the depth of invasion and the worst pattern of invasion. ${ }^{4}$ Finding novel molecules involved in the malignant behaviors of OTSCC cells will help improve the therapeutic strategy.

lncRNAs are, by definition, a new class of RNAs with the length of $>200$ nucleotides. They do not serve as templates for protein coding..$^{5}$ Increasing evidence has suggested that the abnormal expression of lncRNAs is associated with the initiation 
of many pathological changes during carcinogenesis, such as the deregulated proliferation, apoptosis, migration, and invasion of cancer cells. ${ }^{6,7}$ Homo sapiens' HOXA transcript at the distal tip (HOTTIP) located at the $5^{\prime}$ tip of the HOXA locus was initially identified in primary fibroblasts of vertebrates by Wang et al. ${ }^{8}$ It can promote the trimethylation of histone $\mathrm{H} 3$ lysine 4 and upregulate the expression of multiple $5^{\prime}$ HOXA genes in cis. ${ }^{9}$ The elevated expression of HOTTIP has been observed in a number of cancers, including gastric, ${ }^{10}$ papillary thyroid, ${ }^{11}$ and pancreatic cancers. ${ }^{12}$ HOTTIP overexpression can facilitate tumor growth and metastasis, while its silencing can inhibit tumor growth and metastasis and induce apoptosis. ${ }^{13,14}$ There was only one study by Zhang et $\mathrm{al}^{15}$ on OTSCC, which showed a high expression of HOTTIP in tumor tissues. The mechanisms underlying HOTTIP's role in OTSCC development are unclear.

Abnormal cell proliferation is one of the main mechanisms in carcinogenesis. ${ }^{16}$ Previous studies have indicated that specific shRNA against HOTTIP inhibits cancer cell proliferation by hindering the cell cycle progression in multiple types of cancer cells, such as lung cancer cells ${ }^{17}$ and esophageal squamous carcinoma cells. ${ }^{18}$ Whether HOTTIP also affects the cell cycle progression of OTSCC cells is unknown and needs further investigation. Epithelialmesenchymal transition (EMT) is required by tumor cells to invade and migrate to distal organs. Suppression of EMT may prevent the tumor cells from acquiring a migratory potential. ${ }^{19}$ Therefore, in this study, not only the role of HOTTIP in cell proliferation was explored but also its role in the migration, invasion, and EMT of OTSCC cells was investigated.

The TSCCA and TCA8113 cells with stable low expression of HOTTIP were established, and the proliferation, cell cycle progression, and mobility of these cells were assessed. We found that HOTTIP-silenced OTSCC cells acquired a less aggressive tumor phenotype.

\section{Materials and methods}

\section{Cell culture}

Human OTSCC cell lines CAL-27, TSCCA, and TCA8113 were obtained from Zhongqiaoxinzhou (Shanghai, People's Republic of China) and were cultured in minimum essential medium eagle (Gibco; Carlsbad, CA, USA), eagle's minimum essential medium (ScienCell; San Diego, CA, USA), and 1640 (Gibco) containing 10\% FBS (Hyclone; Logan, UT, USA), respectively. The cells were maintained in a humidified atmosphere of $95 \%$ air and $5 \% \mathrm{CO}_{2}$ at $37^{\circ} \mathrm{C}$.

\section{Construction of HOTTIP-silenced OTSCC cells}

HOTTIP-specific shRNA (target sequence, 5' CGAAGCGCTCAGTAAGAAC 3') and negative control (NC) shRNA were synthesized and inserted into a shRNA expression vector, pRNA-H1.1 (GenScript; Nanjing, People's Republic of China). Transfection of shRNA plasmids was mediated by lipofectamine 2000 (Thermo Fisher Scientific, Waltham, MA, USA) according to the manufacturer's instructions. Stable transfectants were screened by selecting cells resistant to $500 \mu \mathrm{g} / \mathrm{mL}$ of G418 (Invitrogen). The knockdown efficiencies of HOTTIP shRNAs were determined by quantitative real-time PCR.

\section{Cell viability assay}

TSCCA or TCA8113 $\left(3 \times 10^{3}\right.$ cells/well $)$ cells were seeded and cultured in a 96 -well plate at $37^{\circ} \mathrm{C}$ for $12,24,48$, or 72 hours. Cell viability was analyzed by using a Cell Counting Kit-8 (CCK-8; KeyGEN BioTECH; Nanjing, People's Republic of China) following the manufacturer's protocol.

\section{Doubling time assay}

TSCCA or TCA8113 cells were seeded in 24-well plates at a density of $5 \times 10^{4}$ in triplicate and allowed to grow for 24 , 48 , or 72 hours. Then, the number of cells was counted using an hemocytometer. The cell doubling rate at each time point was calculated via the following formula: ${ }^{20,21}\left(t-t_{i}\right) \times \log 2 /$ $\left(\log N_{t}-\log N_{i}\right)$, where $N_{t}$ and $N_{i}$ are the cell numbers at specific time points $t$ and $t$, respectively. The mean cell doubling time was averaged from the three time points.

\section{D clonogenic assay}

Cells were digested and seeded in $35 \mathrm{~mm}$ dishes ( 500 cells/well) at $37^{\circ} \mathrm{C}$. After 40 days, cells were fixed in $4 \%$ paraformaldehyde (Sinopharm; Shanghai, People's Republic of China) for 20 minutes and stained with Wright-Giemsa staining solution (Nanjing Jiancheng Bioengineering Institute; Nanjing, People's Republic of China) for 5 minutes. A colony image was acquired under an inverted phase-contrast microscope (Motic; Kowloon, Hong Kong). The colony formation rates were determined as formed colonies $/ 500$.

\section{Flow cytometry}

For cell cycle analysis, cells seeded in 6-well plates at a density of $1 \times 10^{5}$ cells/well were fixed in $70 \%$ cold ethanol for 2 hours at $4^{\circ} \mathrm{C}$, washed with $\mathrm{PBS}$, and stained with propidium iodide (PI) solution (Beyotime Institute of Biotechnology; Haimen, Jiangsu, People's Republic of China). Apoptotic cells were assessed using a PI/Annexin V-FITC apoptosis detection kit 
(Beyotime Institute of Biotechnology) according to the manufacturer's protocol. All cell samples were subjected to flow cytometry (BD Biosciences; Franklin Lakes, NJ, USA).

\section{Hoechst and immunofluorescence staining}

TSCCA or TCA8113 cells were grown on coverslips placed in 12-well plates at a density of $1 \times 10^{5}$ cells/well. For Hoechst staining, cells were incubated with Hoechst (Beyotime Institute of Biotechnology) for 5 minutes. For immunofluorescence staining, cells were fixed with $4 \%$ paraformaldehyde (Sinopharm) and permeabilized with $0.1 \%$ Triton-X 100 (Beyotime Institute of Biotechnology) at room temperature. Subsequently, cells were blocked with goat serum (Solarbio; Beijing, People's Republic of China) and incubated with E-cadherin antibody (Cell Signaling Technology; Danvers, MA, USA) at $4{ }^{\circ} \mathrm{C}$ overnight and then with $\mathrm{Cy}-3$-conjugated goat anti-rabbit IgG secondary antibody (Beyotime Institute of Biotechnology) for 60 minutes at room temperature. DAPI was used to stain cell nuclei. Cell images were taken under a fluorescence microscope (Olympus; Tokyo, Japan).

\section{Cell migration assay}

Cancer cell migration ability was determined by scratch wound-healing assay. Cells were seeded in 6-well plates at a density of $1 \times 10^{5}$ cells/well, grown until reaching a confluence of $90 \%$, and then were treated with mitomycin C $(1 \mu \mathrm{g} / \mathrm{mL}$; Sigma-Aldrich; St Louis, MO, USA) for 1 hour. For woundhealing assay, a linear wound was generated across the cell monolayer by a sterile $200 \mu \mathrm{L}$ pipette tip. Thereafter, the cell monolayer was washed with serum-free medium to remove floating cells or debris, and then maintained in a humidified atmosphere of $5 \% \mathrm{CO}_{2}$ at $37^{\circ} \mathrm{C}$ for additional 24 hours. Images were taken at 0 hour and 24 hours under an inverted phase-contrast microscope (Motic). The cell migration rate was calculated as the percentage of closure.

\section{Cell invasion assay}

Transwell inserts with $8 \mu \mathrm{m}$ pores (Corning; Cambridge, MA, USA) were coated with $40 \mu \mathrm{L}$ pre-diluted matrigel (BD Biosciences), and $200 \mu \mathrm{L}$ of cell suspension $\left(1 \times 10^{4}\right.$ cells/ well) was added to the upper chambers. The lower chamber was filled with medium containing $20 \% \mathrm{FBS}$. After 48 hours, cells that passed through the chamber membrane were fixed with 4\% paraformaldehyde (Sinopharm) for 20 minutes and stained with $0.5 \%$ crystal violet (Amresco; Dallas, TX, USA) for 5 minutes. The number of invasive cells was counted under a microscope (Motic).

\section{Qualitative real-time PCR}

Total cell RNAs were obtained using TRIpure Reagent (BioTeke; Beijing, People's Republic of China), and cDNAs using the RNAs as template were obtained via Super M-MLV reverse transcriptase (BioTeke). A qualitative real-time PCR was performed using SYBR Green Mastermix (Solarbio), and specific primer pairs on an Exicycler ${ }^{\mathrm{TM}} 96$ real-time PCR machine (Bioneer; Daejeon, Korea). The primers were as follows: HOTTIP forward, 5'-AATGTAAGTGTCGCCCAATA-3', HOTTIP reverse, 5'-AGTCAGGGAGAAGGTAAA-3'; E-cadherin forward, 5'-GAACGCATTGCCACATACAC-3', E-cadherin reverse, 5'-TGGTGTAAGCGATGGCGGCA-3'; GAPDH forward 5'-GAAGGTCGGAGTCAACGGAT-3', GAPDH reverse 5'-CCTGGAAGATGGTGATGGGAT-3'. The relative quantification values were calculated via $2^{-\triangle A C T}$ and normalized to GAPDH.

\section{Western blotting}

Whole-cell lysates were obtained using RIPA buffer (Beyotime Institute of Biotechnology) for protein extraction. Protein samples $(10-40 \mu \mathrm{g})$ were loaded onto the SDS-PAGE gel and then transferred onto polyvinylidene difluoride membranes (Millipore; Burlington, MA, USA) by electroblotting. For immunoblotting, the membranes were incubated with primary antibodies including Bcl-2 (BOSTER; Wuhan, People's Republic of China), Bax (Proteintech; Wuhan, People's Republic of China), cyclins B, D1, E, cleaved-caspase-3, cleaved-PARP, and E-cadherin (Cell Signaling Technology) at $4^{\circ} \mathrm{C}$ overnight and then with HRPconjugated goat anti-mouse (Beyotime Institute of Biotechnology) or anti-rabbit IgG (Beyotime Institute of Biotechnology) at $37^{\circ} \mathrm{C}$ for 45 minutes. ECL reagent (Beyotime Institute of Biotechnology) was used for protein blot visualization, and the band intensities were quantified by Gel-Pro-Analyzer. GAPDH was used as the internal reference.

\section{Xenografts}

In vivo, TSCCA and TCA8113 cells transduced with HOTTIP shRNA or NC shRNA were subcutaneously injected into the right flank of $\mathrm{BALB} / \mathrm{c}$ nude mice at $2 \times 10^{6}$ cells per mouse ( $n=6$ in each group). Tumor size was measured every 3 days, and tumor volumes were calculated following $\mathrm{V}=\mathrm{a}^{2} \times \mathrm{b} \times 0.5$, where $a$ is the tumor width and $b$ is the tumor length. Then mice were sacrificed, and the weight of each tumor was recorded. All animal experiments were approved by the Experimental Animal Ethics Committee of the Second Affiliated Hospital of Harbin Medical University, and all procedures conformed to the National Institutes of Health guidelines for the care and use of laboratory animals and laboratory procedures. 


\section{H\&E staining}

The tumors were harvested on day 21 after tumor cell injection, fixed in $4 \%$ paraformaldehyde (Sinopharm), and embedded in paraffin. The $5 \mu \mathrm{m}$-thick sections were stained with $\mathrm{H} \& \mathrm{E}$ according to the standard protocol.

\section{Statistical analysis}

Data were represented as mean \pm SD and analyzed with GraphPad Prism 6. $P$-values were calculated using ANOVA for multiple comparisons. A $P$-value of $<0.05$ was considered to be statistically significant (presented in each figure legend as $* P<0.05, * * P<0.01)$.

\section{Results}

\section{Establishment of HOTTIP-silenced OTSCC cells}

HOTTIP expression levels in CAL-27, TSCCA, and TCA8113 were first determined with real-time PCR. The results showed that TSCCA and TCA8113 cells had higher expression of HOTTIP (Figure 1A). Therefore, we decided to use these two cell lines for the following loss-of-function assay of HOTTIP. TSCCA and TCA8113 cells transfected with HOTTIP shRNA or NC shRNA were selected with G418. Cells resistant to G418 were subjected to real-time PCR analysis. Our data showed that the HOTTIP-specific shRNA, but not the NC shRNA, significantly reduced HOTTIP expression in TSCCA and TCA8113 cells (Figure 1B and C).

\section{Suppression of HOTTIP inhibited OTSCC cell growth}

The growth of TSCCA and TCA8113 cells transfected NC or HOTTIP shRNA was detected via CCK-8, cell counting, and colony formation assays. As shown in Figure 2A and B, knockdown of HOTTIP significantly delayed cell proliferation. HOTTIP silencing prolonged the cell doubling time from $27.13 \pm 3.02$ hours to $43.45 \pm 2.83$ hours in TSCCA cells and from $39.43 \pm 0.69$ hours to $56.23 \pm 6.23$ hours in TCA8113 cells (Figure 2C and D). Furthermore, inhibition of HOTTIP reduced the number of colonies by $70.20 \% \pm 6.4 \%$ in TSCCA cells (Figure 2E) and by $74.93 \% \pm 4.6 \%$ in TCA8113 cells (Figure 2F). In both cell lines, HOTTIP knockdown resulted in a delay of cell cycle progression. More cells were arrested in G1 phase when HOTTIP was knocked down $(73.07 \% \pm 2.27 \%$ vs $61.12 \% \pm 4.34 \%=$ HOTTIP-silenced TSCCA cells vs NC cells, $69.11 \% \pm 4.68 \%$ vs $57.72 \% \pm 2.51 \%=$ HOTTIP-silenced TCA 8113 cells vs NC cells; Figure $2 \mathrm{G}$ and $\mathrm{H}$ ). In addition, Western blot analysis revealed that HOTTIP silencing reduced the protein expression of important cell cycle regulators, such as cyclin B (by $64.03 \% \pm 3.90 \%$ ), cyclin D1 (by $59.37 \% \pm 9.55 \%$ ), and cyclin E (by $78.98 \% \pm 4.91 \%$ ) in TSCCA cells (Figure 2I). Consistently, HOTTIP silencing downregulated the expression of cyclin B, cyclin D1, and cyclin E by $59.89 \% \pm 4.78 \%$, $63.75 \% \pm 5.08 \%$, and $70.33 \% \pm 0.68 \%$ in TCA 8113 cells (Figure 2J). These results demonstrated that HOTTIP silencing reduced the proliferation of OTSCC cells and arrested them at G1 phase.

\section{Silencing of HOTTIP induced cell apoptosis in OTSCC cells}

Cell apoptosis was detected by flow cytometry using a PI/ Annexin V-FITC apoptosis detection kit and by Hoechst staining. Figure $3 \mathrm{~A}$ and B shows that knockdown of HOTTIP triggered apoptosis both in TSCCA and in TCA8113 cells. The percentage of apoptotic cells was increased from $3.12 \% \pm 0.21 \%$ to $14.88 \% \pm 2.03 \%$ in TSCCA cells and from $2.61 \% \pm 0.27 \%$ to $21.22 \% \pm 3.19 \%$ in TCA 8113 cells when HOTTIP was silenced. Similarly, HOTTIP silencing
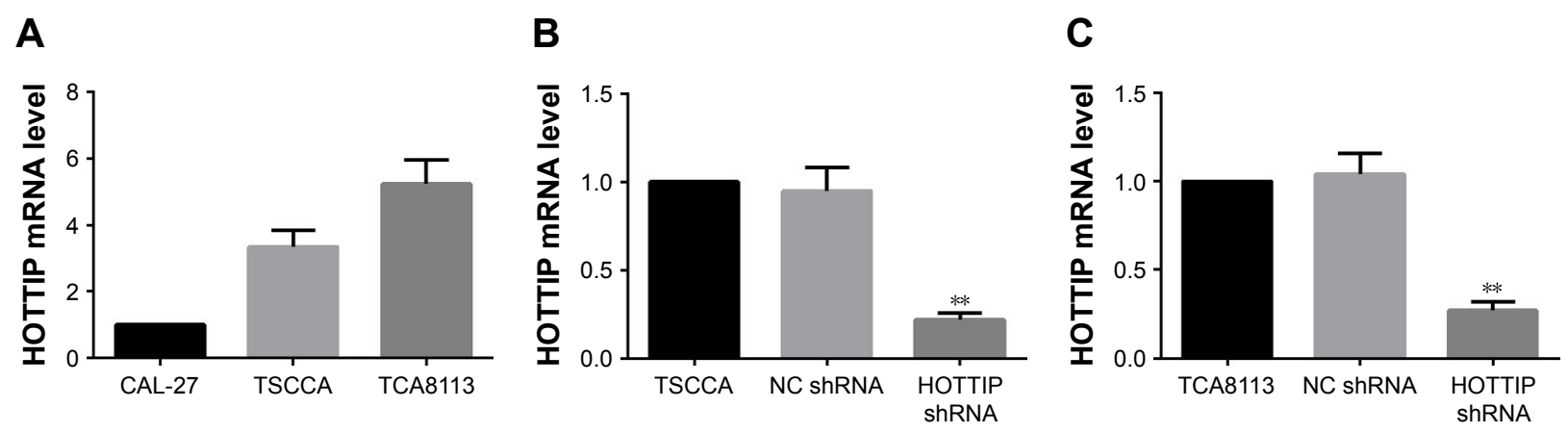

Figure I Establishment of HOTTIP-silenced OTSCC cell strains.

Notes: (A) Expression levels of HOTTIP were detected by real-time PCR in human tongue squamous carcinoma cell lines. (B and C) TSCCA and TCA8II 3 cells were transfected with HOTTIP shRNA or NC shRNA, and then selected for stable expression. The levels of HOTTIP mRNA in cells were examined by real-time PCR. GAPDH served as the internal control. Compared with NC shRNA, **P-value $<0.01$.

Abbreviations: HOTTIP, HOXA transcript at the distal tip; OTSCC, oral tongue squamous cell carcinoma; GAPDH, glyceraldehyde-3-phosphate dehydrogenase; NC, negative control. 
robustly elevated the fraction of Hoechst-positive cells (Figure 3C and D). Furthermore, results from Western blot assay showed that silencing of HOTTIP increased the levels of pro-apoptotic proteins such as cleaved-caspase-3, Bax, and cleaved-PARP, whereas this downregulated anti-apoptotic Bcl-2 (Figure 3E and F).

\section{Knockdown of HOTTIP inhibited cell migration and invasion in vitro}

Scratch wound healing and matrigel-based transwell assays were used to analyze the motility and invasiveness of TSCCA and TCA8113 cells. As depicted in Figure 4A, HOTTIP shRNA significantly decreased the migratory and

A

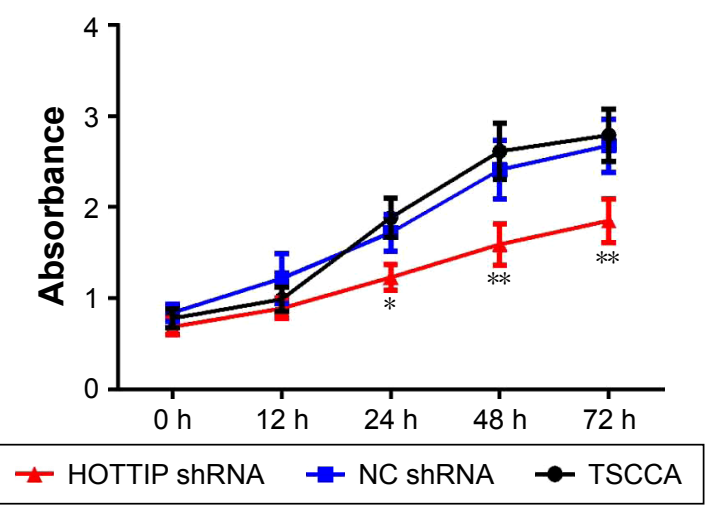

C

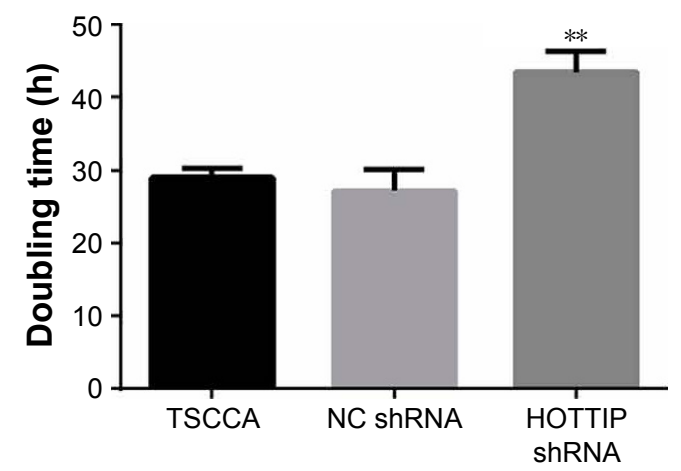

E
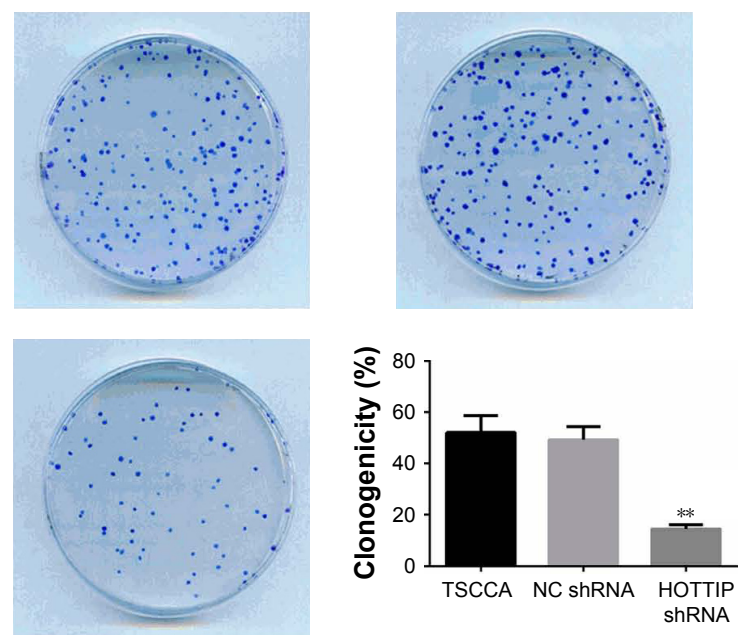

invasive ability of TSCCA cells by $55.83 \% \pm 1.84 \%$ and $60.37 \% \pm 7.80 \%$, respectively. Similarly, knockdown of HOTTIP reduced motility by $30.93 \% \pm 0.73 \%$ and invasiveness by $42.62 \% \pm 8.92 \%$ in TCA 8113 cells (Figure $4 \mathrm{~B}$ ). In addition, the expression of E-cadherin was measured by immunofluorescence assay and Western blotting. Compared with cells transfected with NC shRNA, E-cadherin expression was upregulated in the HOTTIP-silenced cells (Figure 4C-F).

\section{Silencing of HOTTIP suppressed xenograft growth in vivo}

In order to validate the in vitro findings, the effect of HOTTIP downregulation on the growth of OTSCC cells was

B

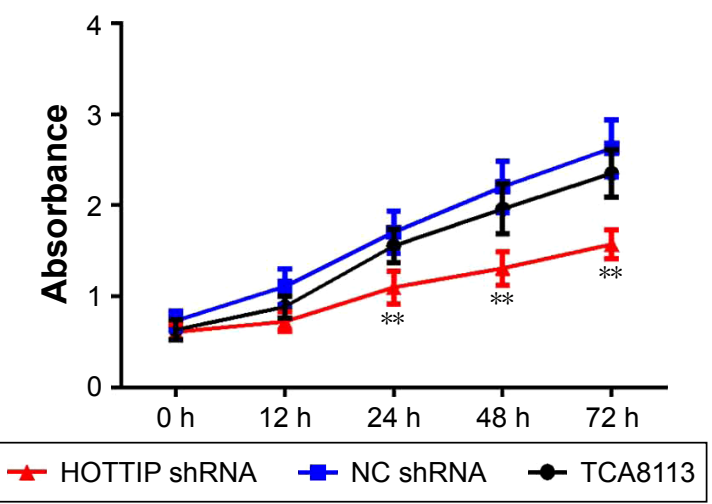

D

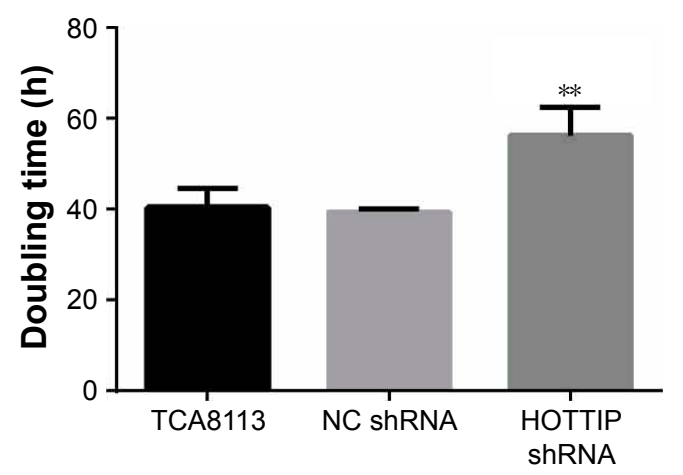

$\mathbf{F}$
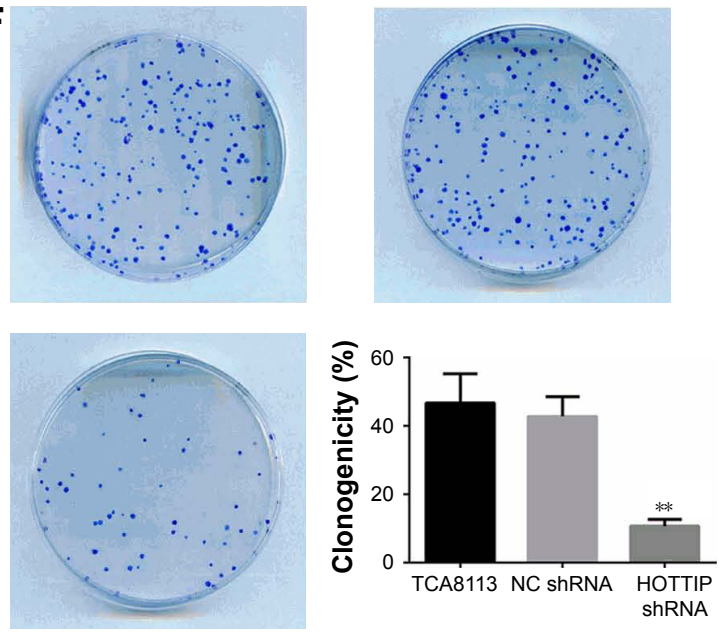

Figure 2 (Continued) 

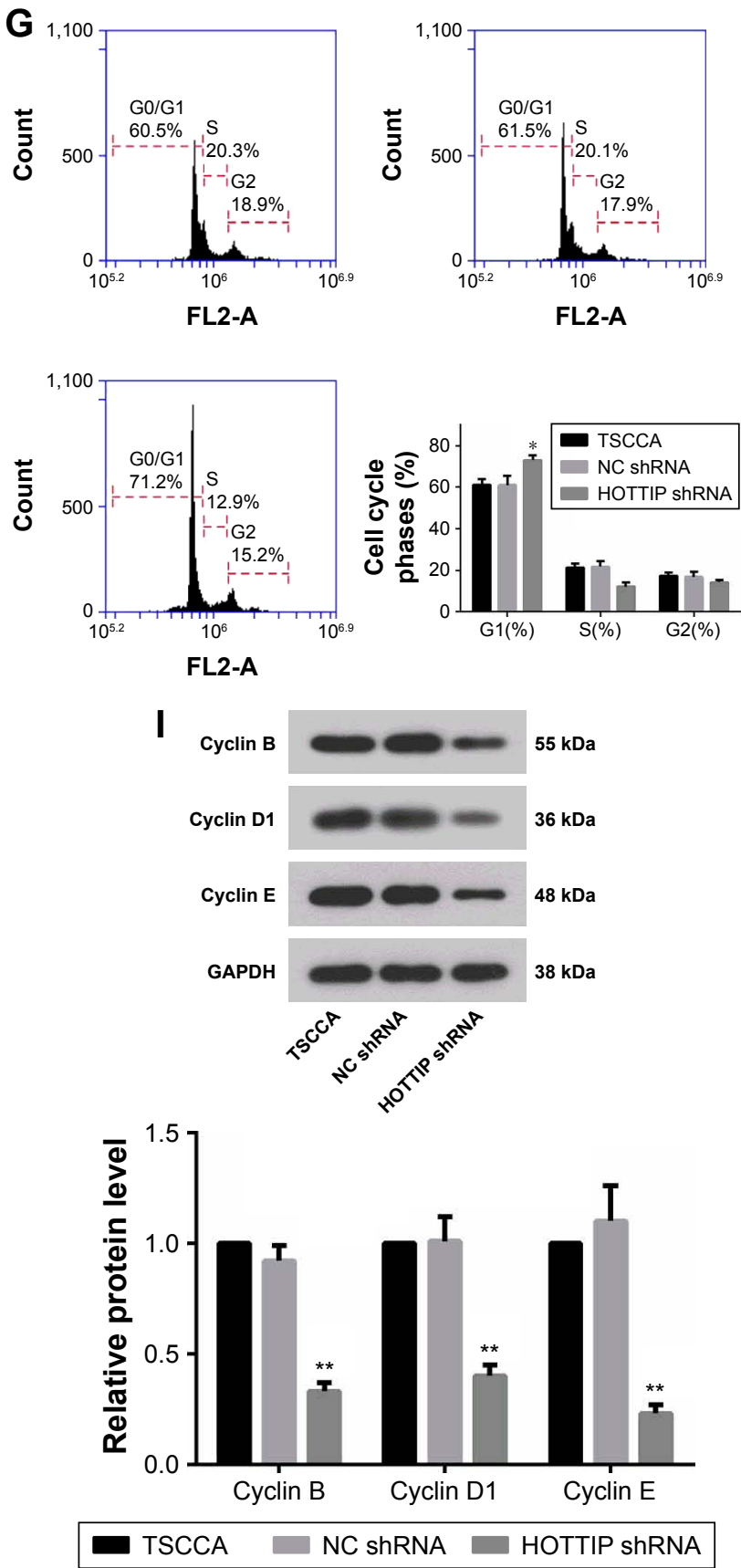
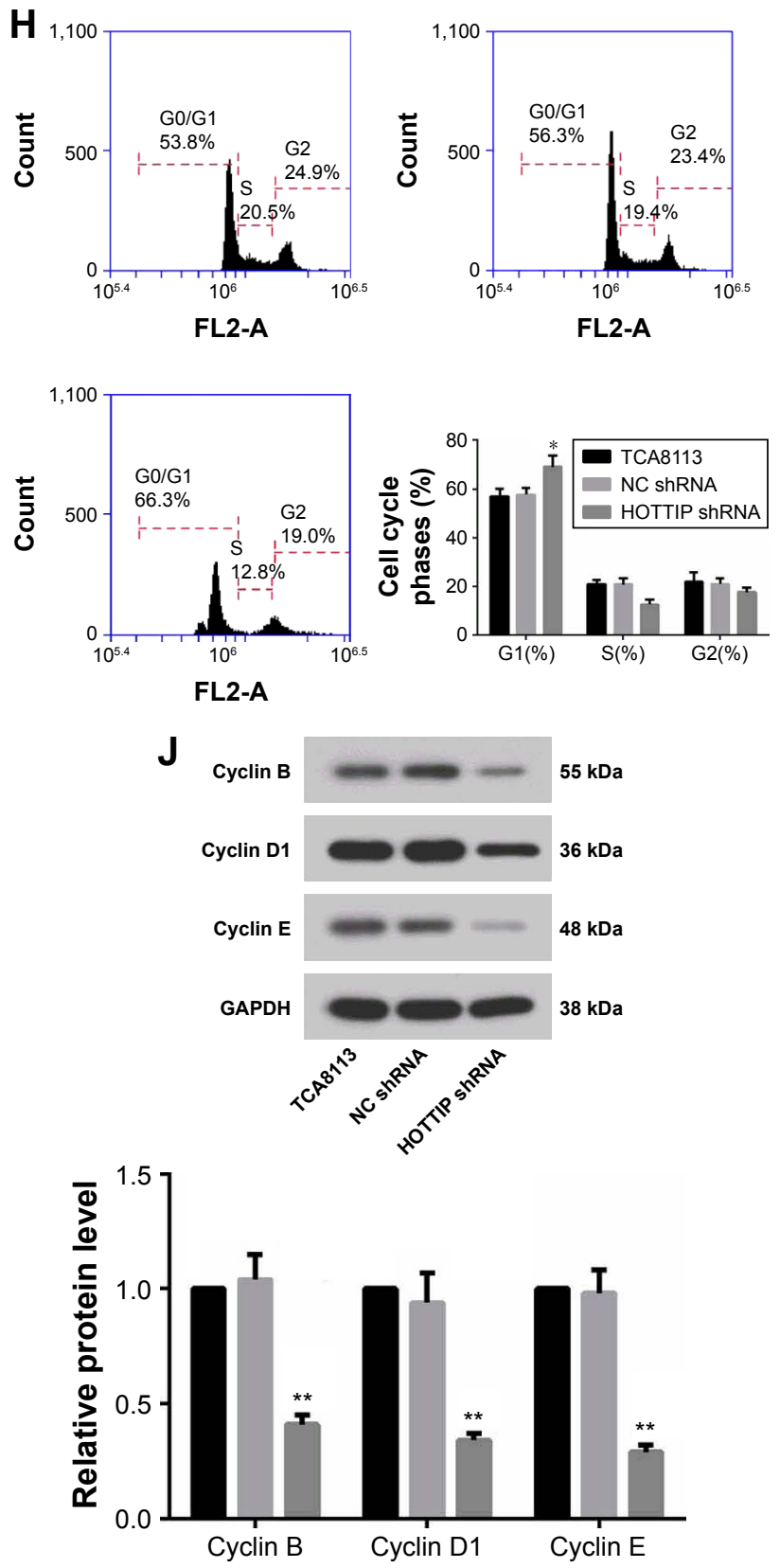

TCA8113 NC shRNA HOTTIP shRNA

Figure 2 Silencing of HOTTIP inhibited proliferation and arrested cell cycle of OTSCC cells.

Notes: (A and B) The proliferation of HOTTIP-silenced TSCCA and TCA8II 3 cells was assessed by the CCK-8 assay. (C and D) Doubling time was determined by cell counting. (E and $\mathbf{F}$ ) Colony formation rate was detected by the 2D clonogenic assay. ( $\mathbf{G}$ and $\mathbf{H}$ ) Cell cycle was analyzed by flow cytometry. (I and J) The protein expression levels of cyclin B, DI, and E were determined by Western blot analysis. $* P<0.05$ and $* * P<0.01$ compared with NC shRNA.

Abbreviations: HOTTIP, HOXA transcript at the distal tip; OTSCC, oral tongue squamous cell carcinoma; CCK-8, Cell Counting Kit-8; NC, negative control; h, hours.

further analyzed in a xenograft tumor model. We found that HOTTIP silencing decreased the volumes of tumors formed by TSCCA cells by $81.73 \% \pm 2.22 \%$ and those formed by TCA 8113 cells by $69.02 \% \pm 12.05 \%$ on day 21 post injection (Figure 5A and B). Meanwhile, tumor weight was also decreased in HOTTIP-silenced TSCCA and TCA8113 cells (Figure 5C and D). Furthermore, histological examination showed marked cytoplasm lysis and nuclear condensation in the tumor generated by HOTTIP-silenced cells (Figure 5E and F). Silencing of HOTTIP in the xenograft tumors was confirmed by qualitative real-time PCR (Figure 5G and H).

\section{HOTTIP was a prognostic factor for patients with HNSC}

OTSCC belongs to head and neck squamous carcinoma (HNSC). Gene expression profiling interactive analysis 


\section{A}

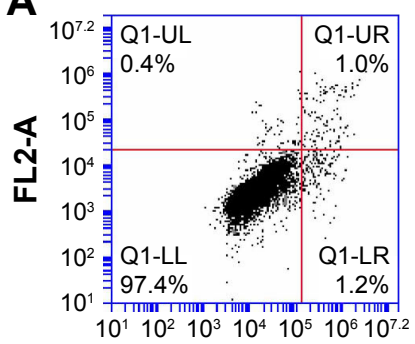

FL1-A

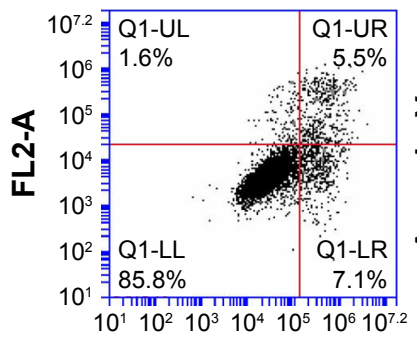

FL1-A

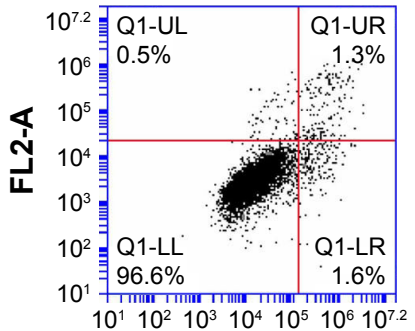

FL1-A

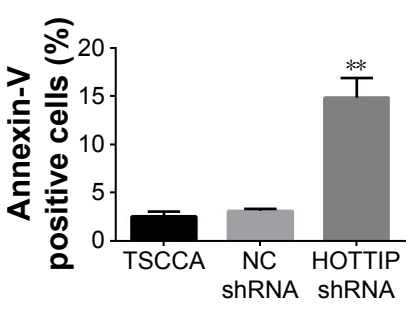

C
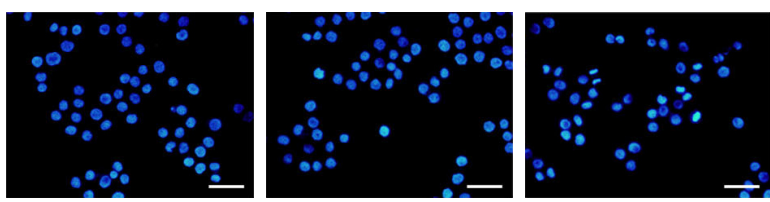

E
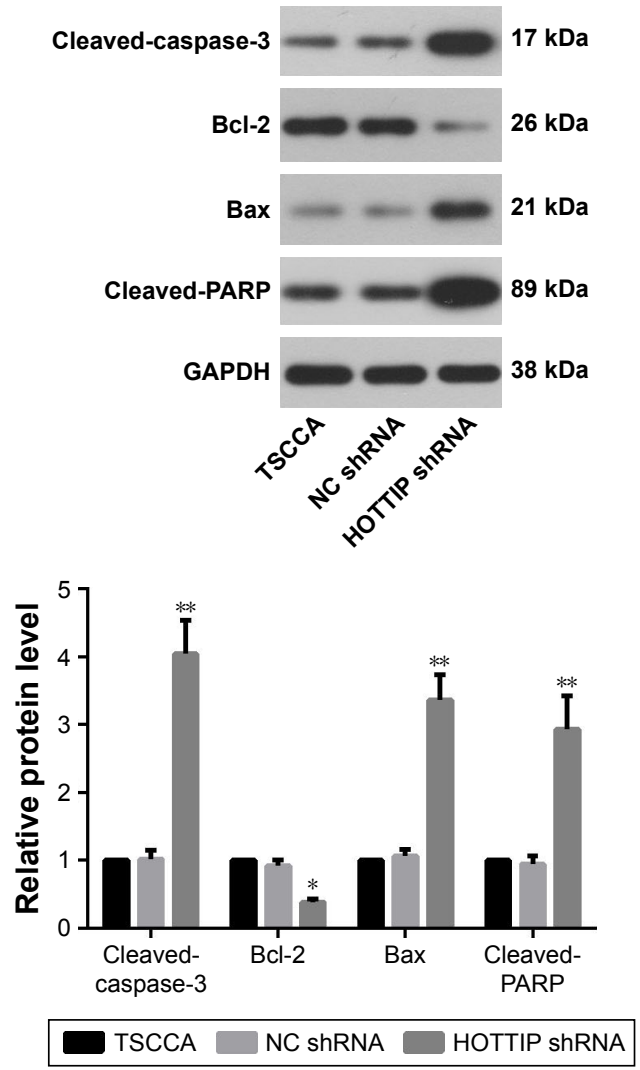

B

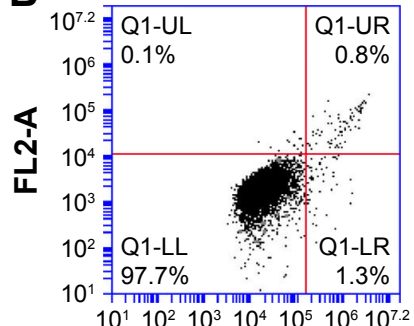

FL1-A

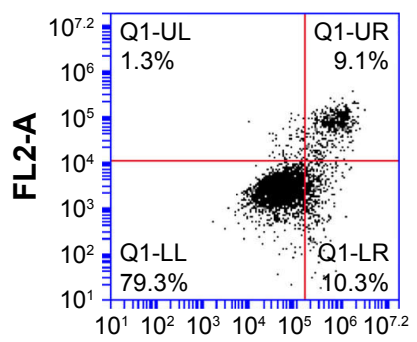

FL1-A

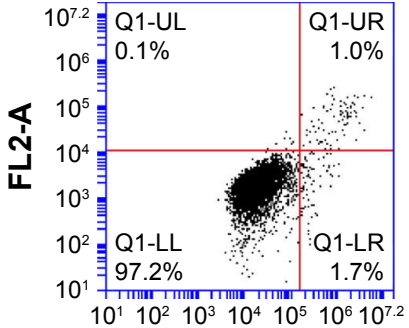

FL1-A

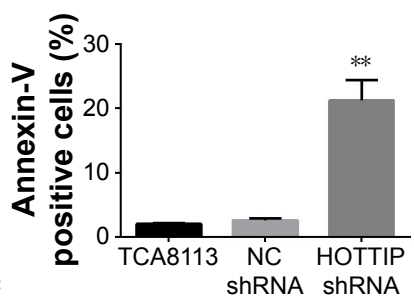

D
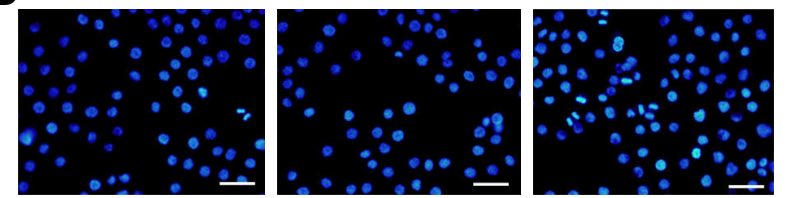

F
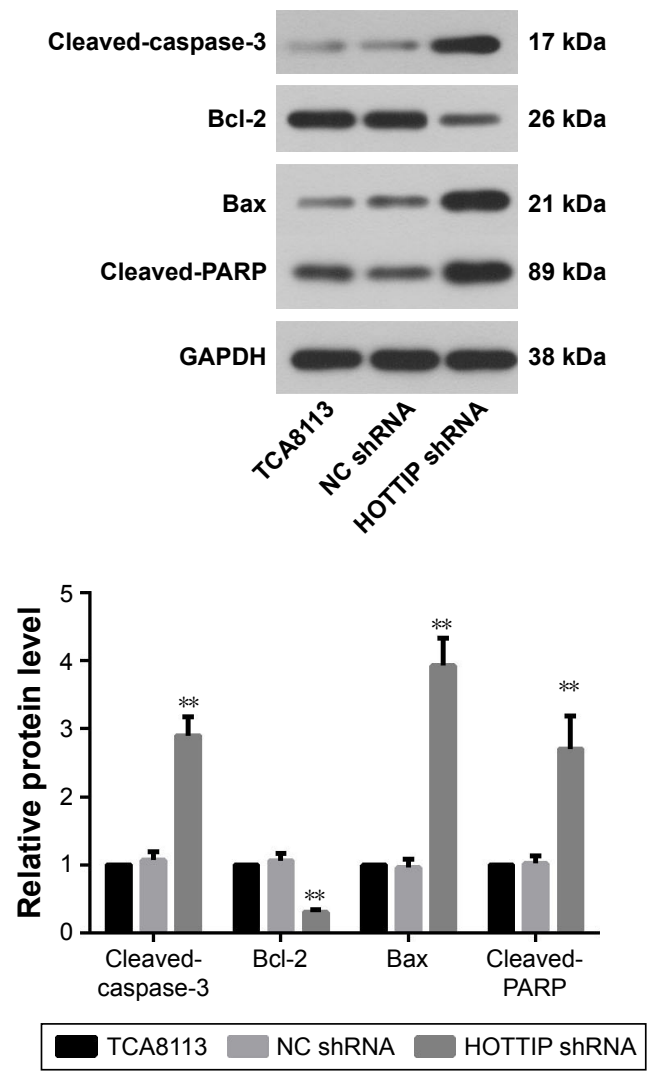

Figure 3 Knockdown of HOTTIP induced apoptosis of OTSCC cells.

Notes: (A and B) Apoptosis of TSCCA and TCA8II3 cells was examined by flow cytometry. (C and D) Cells were incubated with Hoechst stains, and the images of apoptotic cells were taken under a fluorescent microscope (scale bar $=50 \mu \mathrm{m}$ ). ( $\mathbf{E}$ and $\mathbf{F}$ ) The expression levels of apoptosis markers were detected by Western blot analysis with GAPDH as the internal control. $* P<0.05$ and $* * P<0.01$ compared with NC shRNA.

Abbreviations: HOTTIP, HOXA transcript at the distal tip; OTSCC, oral tongue squamous cell carcinoma; GAPDH, glyceraldehyde-3-phosphate dehydrogenase; NC, negative control. 
A
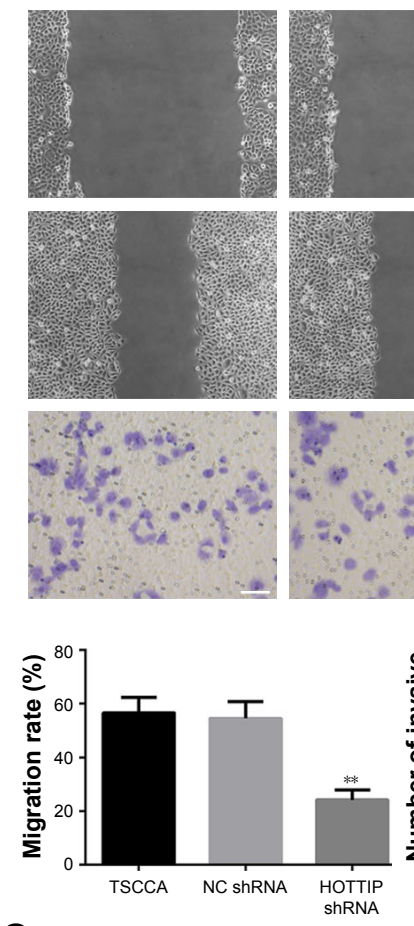

C
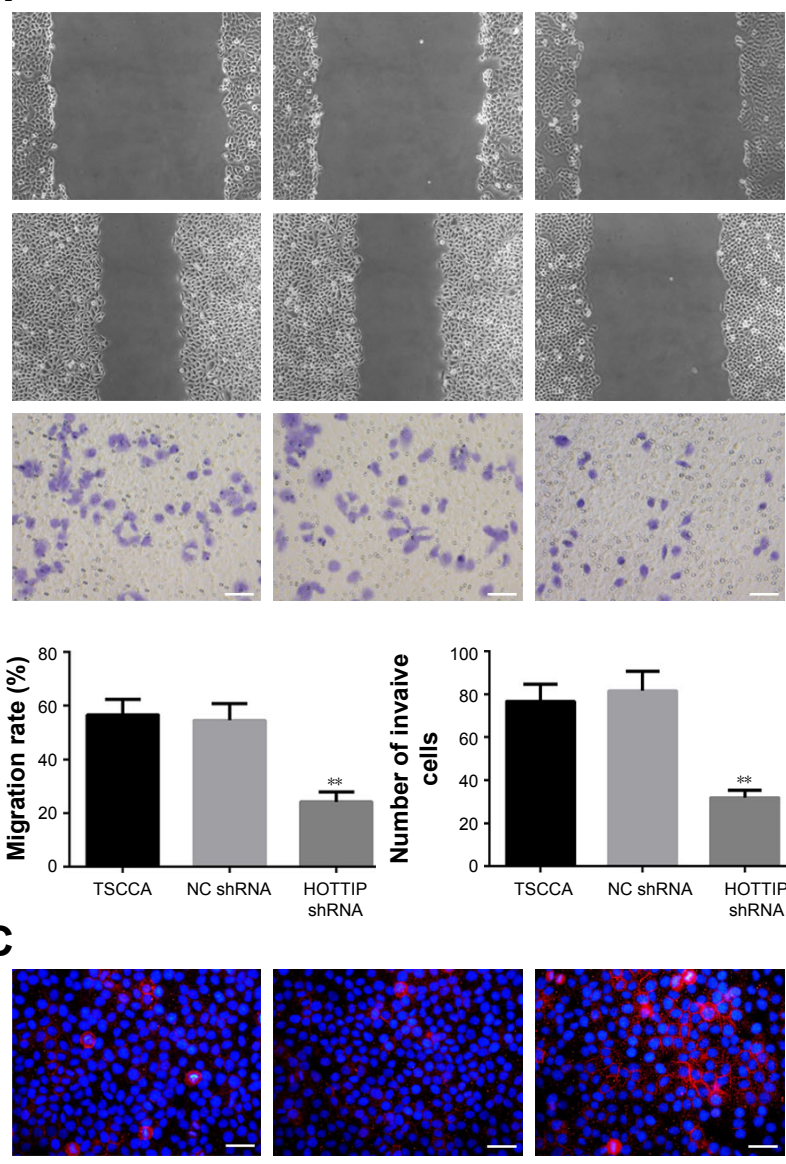

$\mathbf{E}$
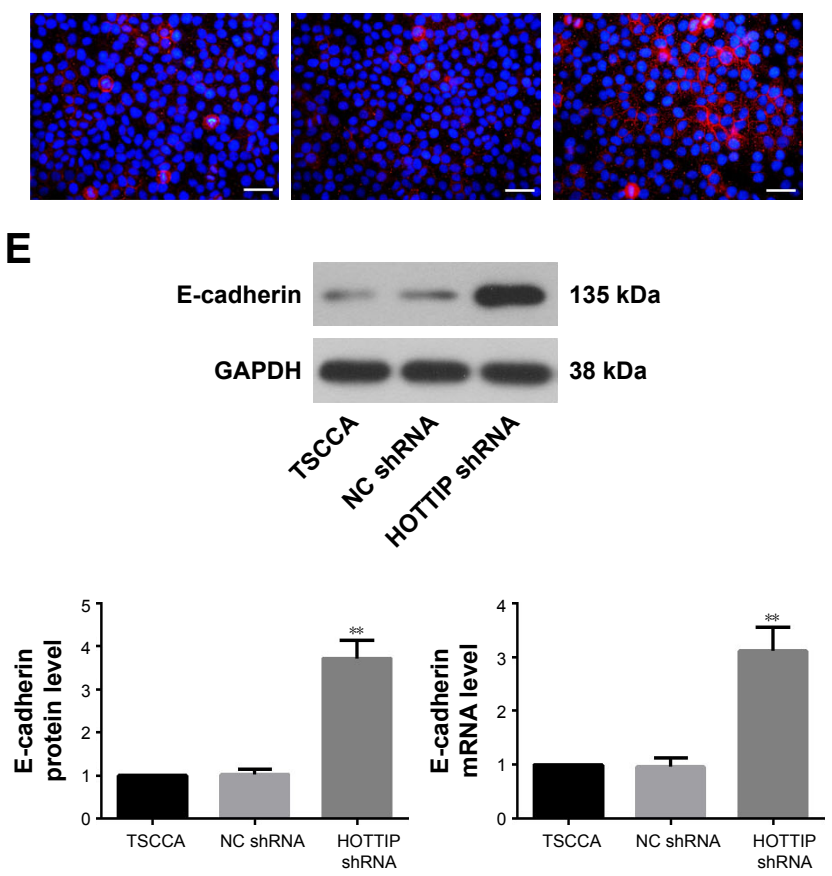

B
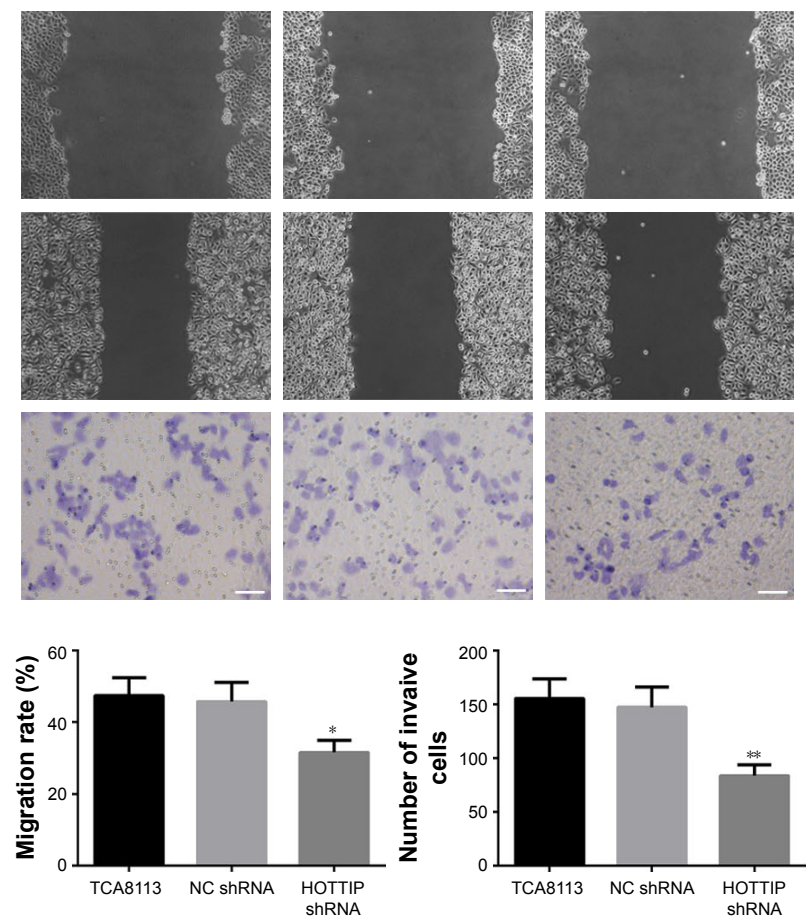

D
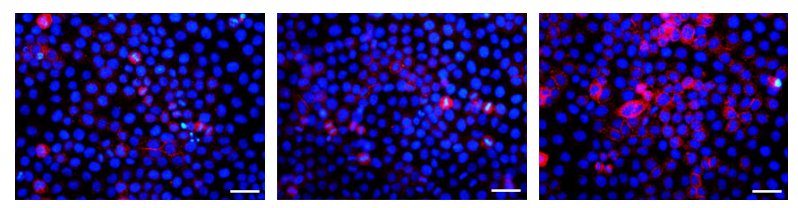

$\mathbf{F}$
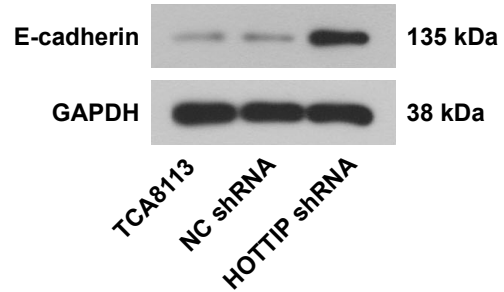
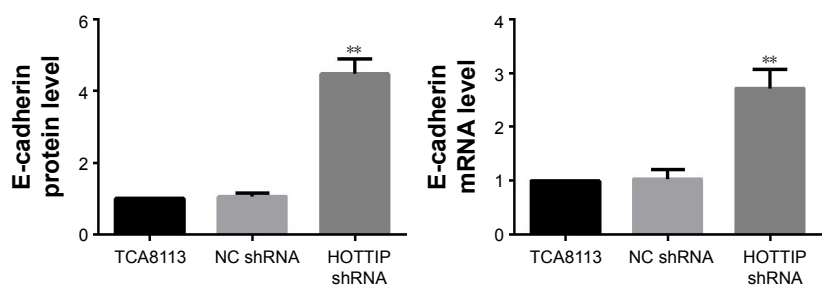

Figure 4 HOTTIP silencing suppressed the migration and invasion of OTSCC cells.

Notes: (A and B) Scratch wound healing assay and Matrigel-based transwell assay were used to evaluate the migration and invasion of TSCCA and TCA8I I 3 cells (scale bar=100 $\mu \mathrm{m}$ ). (C and D) Immunofluorescence assay using E-cadherin antibody (red) was performed to detect the expression of E-cadherin in OTSCC cells. DAPI was used to visualize the cell nucleus (blue; scale bar $=50 \mu \mathrm{m}$ ). (E and $\mathbf{F}$ ) E-cadherin protein and mRNA levels were determined by Western blotting and real-time PCR, respectively. $* P<0.05$ and $* * P<0.01$ compared with NC shRNA.

Abbreviations: HOTTIP, HOXA transcript at the distal tip; OTSCC, oral tongue squamous cell carcinoma; NC, negative control.

(GEPIA) was carried out to evaluate the potential of HOTTIP as a prognostic factor in HNSC. Gene expression profiling interactive analysis (GEPIA) was carried out, and the results were shown as boxplot and survival plot. As shown in Figure S1A, the expression level of HOTTIP was higher in tumor tissues than in nontumor tissues, although the data did not reach a significant level. Furthermore, as shown in Figure S1B, the overall survival rate of HNSC patients with high HOTTIP was significantly lower than those with low HOTTIP $(P=0.016)$. 
A

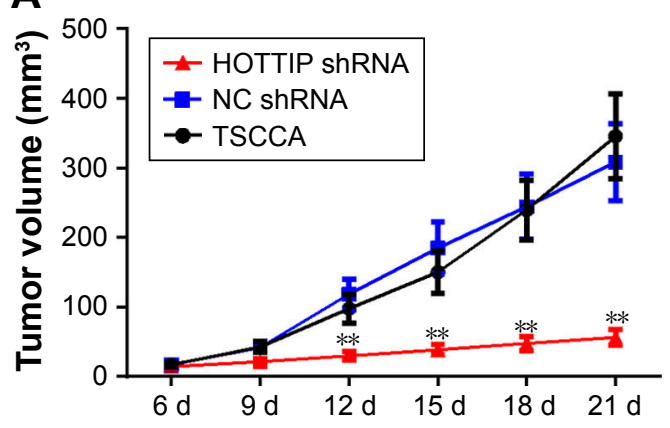

C

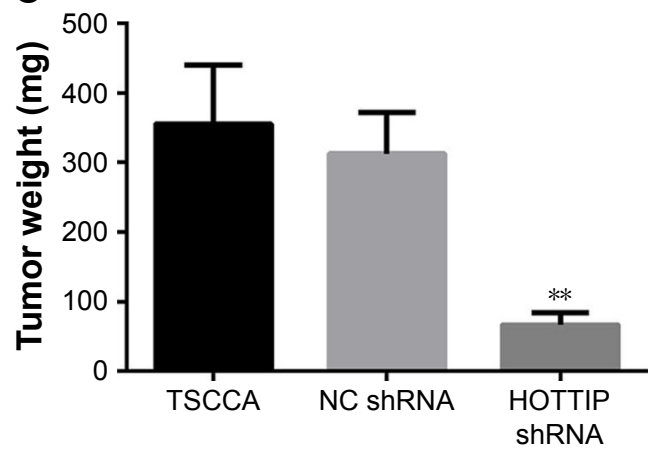

B

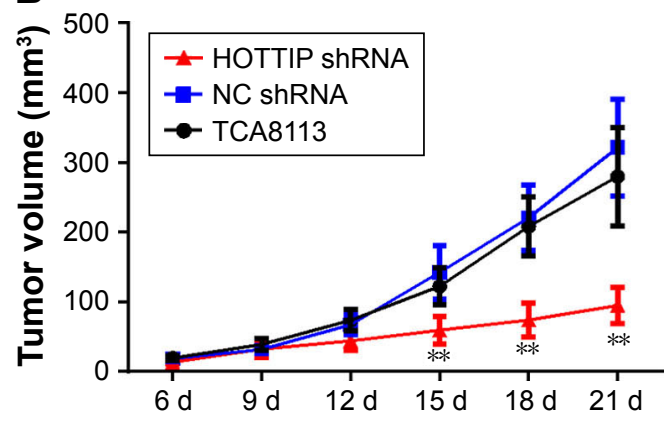

D

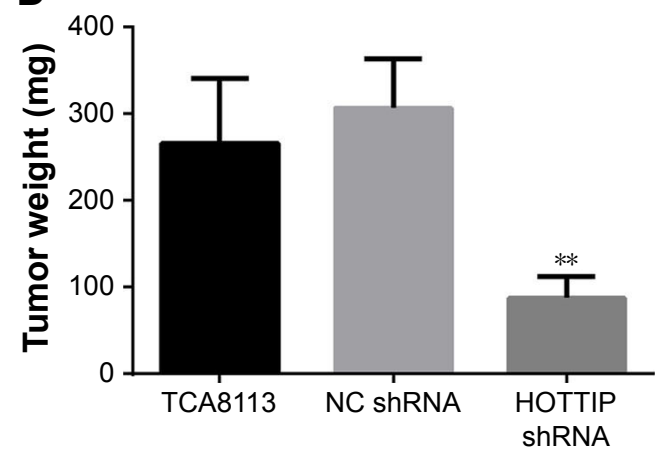

E
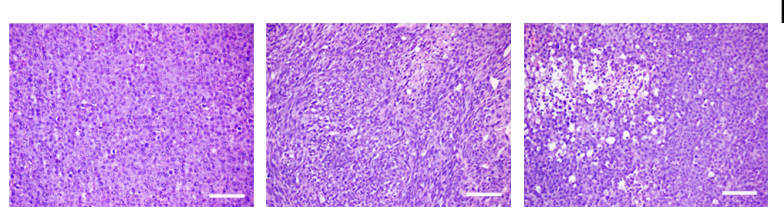

$\mathbf{F}$
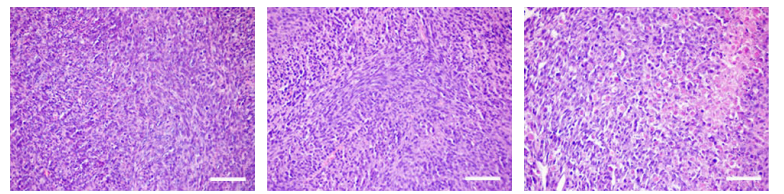

G
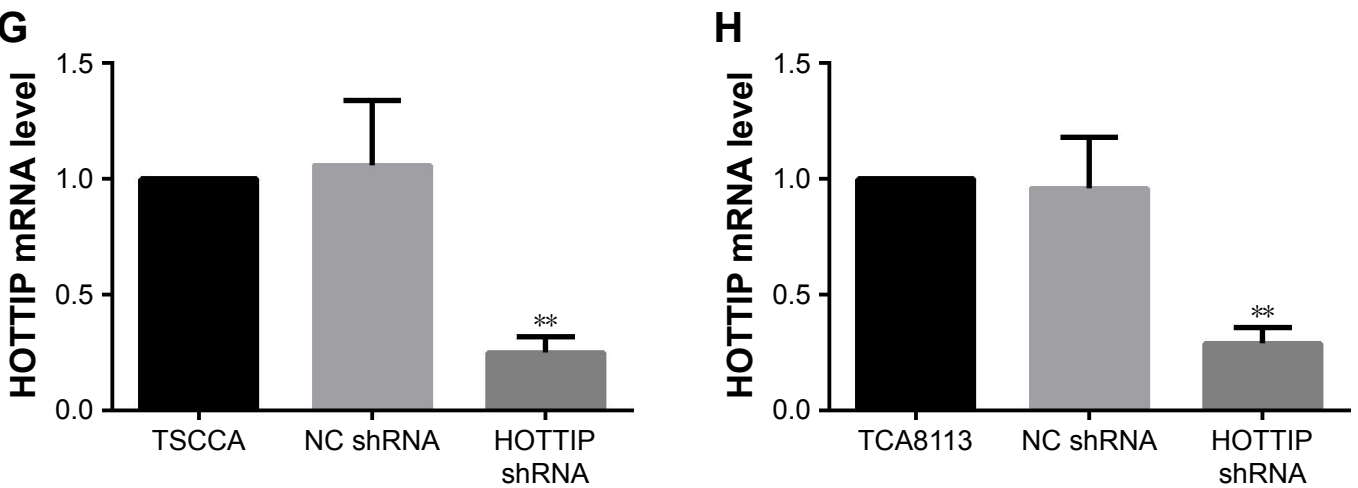

Figure 5 Inhibition of HOTTIP delayed tumor formation in vivo.

Notes: (A and B) Parental and transfected OTSCC cells with HOTTIP shRNA or NC shRNA were inoculated subcutaneously into nude mice, and xenograft volumes were measured every 3 days. ( $C$ and $\mathbf{D}$ ) By the end of week 3 , the mice were sacrificed, and the xenograft tumors were excised and weighted. (E and $\mathbf{F}$ ) H\&E staining was used to investigate the histological change in tumor tissues (scale bar $=100 \mu \mathrm{m})$. ( $\mathbf{G}$ and $\mathbf{H}$ ) The mRNA levels of HOTTIP in the tumors were analyzed by real-time PCR. $* * P<0.0 \mathrm{I}$ compared with NC shRNA.

Abbreviations: HOTTIP, HOXA transcript at the distal tip; OTSCC, oral tongue squamous cell carcinoma; NC, negative control.

\section{Discussion}

Previous studies showed that HOTTIP is markedly increased in various cancer types, and such elevation is correlated with cancer progression. Liu et a ${ }^{13}$ reported that knockdown of HOTTIP inhibited colorectal cancer cell proliferation and migration by targeting SGK1. Lin et $\mathrm{al}^{14}$ identified HOTTIP as a potential diagnostic marker, and they demonstrated that HOTTIP modulated HOXA13 to facilitate the growth and metastasis of esophageal squamous carcinoma cells in vitro. HOTTIP has also been shown as a tumor cell growth-promoting molecule in lung adenocarcinoma ${ }^{22}$ and prostate cancer. ${ }^{23}$ The expression of HOTTIP was high in OTSCC tissues. ${ }^{15}$ 
Therefore, loss-of-function study was performed to investigate the role of HOTTIP in the development of OTSCC. We found that two OTSCC cell lines with stable low HOTTIP expression acquired a less malignant phenotype.

Excessive tumor cell proliferation due to abnormal cell cycle is the most important cause of mortality in cancer. The precise control of cell cycle - from gap phase 1 to DNA synthesis phase $(\mathrm{G} 1 / \mathrm{S})$ and from gap phase 2 to mitosis phase $(\mathrm{G} 2 / \mathrm{M})$ - ensures cells to proliferate and divide in a programmed manner. Cyclin family proteins, including cyclins $\mathrm{B}, \mathrm{D}$, and $\mathrm{E}$, work in cooperation with cyclin-dependent kinases to orchestrate the cell cycle. ${ }^{24}$ HOTTIP silencing arrested osteosarcoma cells at G1 stage $^{25}$ and decreased the expression of cyclins B1 and D1 in lung and prostate cancer cells. ${ }^{17,26}$ However, in glioma cells, the HOTTIP overexpression, but not its silencing, significantly decreased cyclin A expression and inhibited cell growth. ${ }^{27}$ These previous findings suggest that HOTTIP may have a discrepant regulatory role in various cancers. In OTSCC cells, our data were in accordance with the previous studies reporting a hindered cell cycle of HOTTIP-silenced cancer cells. To fully elucidate the role of HOTTIP in OTSCC progression, there is a need to upregulate its expression in OTSCC cells with low basal HOTTIP expression, which will be carried out in the near future by many groups. In mammary cancer cells ${ }^{28}$ and endometrial cancer, ${ }^{29}$ the forced expression of HOTTIP could accelerate cell cycle progression and enhance cell proliferation. As the silencing of HOTTIP had antiproliferative effects in OTSCC cells, it is possible that its overexpression may have pro-proliferative effects.

Escape of apoptosis is regarded as a hallmark for therapy failure in cancer. ${ }^{30}$ Knockdown of HOTTIP has been shown to induce apoptosis by increasing Bax expression and decreasing $\mathrm{Bcl}-2$ expression in prostate cancer cells. ${ }^{26}$ Sun et $\mathrm{al}^{31}$ revealed that HOTTIP acted as a competitive endogenous RNA for microRNA-216a, thus preventing Bcl-2 from binding microRNA-216a in lung cancer cells.Our study reveals that HOTTIP knockdown triggered cancer cell apoptosis and altered the expression of Bax and Bcl-2 which was in agreement with the earlier studies. The cleavage of caspase-3 and PARP indicates an activated apoptosis cascade. ${ }^{32,33}$ The elevation of cleaved-caspase- 3 and cleaved-PARP in HOTTIP-silenced cells further confirmed the cell apoptosis results detected with PI/Annexin V-FITC and Hoechst assays. The underlying mechanisms require further investigation.

We next explored the migratory and invasive abilities of OTSCC cells in response to HOTTIP knockdown. Here, we found that silencing of HOTTIP inhibited the migration and invasion of TSCCA and TCA8113 cells. Similar results have also been reported in breast cancer cells ${ }^{34}$ and osteosarcoma cells, ${ }^{35}$ which support our current findings. The enhanced mobility of tumor cells is often associated with the accelerated EMT. EMT not only plays an important role in embryonic development but also drives the dissemination of cancer cells. ${ }^{36}$ Lin et $\mathrm{al}^{14}$ showed that HOTTIP promoted EMT by competitively binding to miR-30b and upregulated the expression of snail 1 in esophageal squamous carcinoma cells. Our study showed an E-cadherin upregulation in HOTTIP-silenced cells. This finding suggests that the inhibitory effects of HOTTIP shRNA on the migration and invasion of OTSCC cells at least attribute to EMT suppression.

As the knockdown of HOTTIP can impair the malignant behaviors of OTSCC cells, it is expected that the tumorigenicity of HOTTIP-silenced cells is decreased in vivo. As expected, we found that the growth of tumors in nude mice formed by the HOTTIP-silenced OTSCC cells was slower than that formed by the control cells. The antigrowth effects induced by HOTTIP silencing in vivo were also previously demonstrated in colorectal cancer cells. ${ }^{37}$ Therefore, HOTTIP may serve as a new therapeutic target in OTSCC.

The database of GEPIA integrates data from the Cancer Genome Atlas and Genotype-Tissue Expression. By analyzing the expression of HOTTIP with the clinic information of HNSC patients summarized in GEPIA, we found that the overall survival rate of HNSC patients with high HOTTIP was significantly lower than those with low HOTTIP. These data revealed HOTTIP as a prognostic indicator in HNSC.

\section{Conclusion}

HOTTIP plays a critical role in regulating cell proliferation, migration, invasion, apoptosis, and tumorigenesis of OTSCC cells. Our data define HOTTIP as a potential target for cancer therapy.

\section{Acknowledgment}

This study was supported by a grant from the Harbin Science and Technology Innovation Talent Project (grant no 2013RFQYJ084).

\section{Disclosure}

The authors report no conflicts of interest in this work.

\section{References}

1. Bello IO, Soini Y, Salo T. Prognostic evaluation of oral tongue cancer: means, markers and perspectives (I). Oral Oncol. 2010;46(9):630-635. 
2. Krishna Rao SV, Mejia G, Roberts-Thomson K, Logan R. Epidemiology of oral cancer in Asia in the past decade - an update (2000-2012). Asian Pac J Cancer Prev. 2013;14(10):5567-5577.

3. Siegel RL, Miller KD, Jemal A. Cancer statistics, 2018. CA Cancer J Clin. 2018;68(1):7-30.

4. Almangush A, Bello IO, Coletta RD, et al. For early-stage oral tongue cancer, depth of invasion and worst pattern of invasion are the strongest pathological predictors for locoregional recurrence and mortality. Virchows Arch. 2015;467(1):39-46.

5. Guttman M, Rinn JL. Modular regulatory principles of large non-coding RNAs. Nature. 2012;482(7385):339-346.

6. Chen X, Fan S, Song E. Noncoding RNAs: New Players in Cancers. Adv Exp Med Biol. 2016;927:1-47.

7. Serghiou S, Kyriakopoulou A, Ioannidis JP. Long noncoding RNAs as novel predictors of survival in human cancer: a systematic review and meta-analysis. Mol Cancer. 2016;15(1):50.

8. Wang KC, Yang YW, Liu B, et al. A long noncoding RNA maintains active chromatin to coordinate homeotic gene expression. Nature. 2011; 472(7341):120-124.

9. Burgess DJ. Non-coding RNA: HOTTIP goes the distance. Nat Rev Genet. 2011;12(5):300.

10. Zhao R, Zhang Y, Zhang X, et al. Exosomal long noncoding RNA HOTTIP as potential novel diagnostic and prognostic biomarker test for gastric cancer. Mol Cancer. 2018;17(1):68.

11. Yuan Q, Liu Y, Fan Y, et al. LncRNA HOTTIP promotes papillary thyroid carcinoma cell proliferation, invasion and migration by regulating miR-637. Int J Biochem Cell Biol. 2018;98:1-9.

12. Li Z, Zhao X, Zhou Y, et al. The long non-coding RNA HOTTIP promotes progression and gemcitabine resistance by regulating HOXA13 in pancreatic cancer. J Transl Med. 2015;13:84.

13. Liu T, Yu T, Hu H, He K. Knockdown of the long non-coding RNA HOTTIP inhibits colorectal cancer cell proliferation and migration and induces apoptosis by targeting SGK1. Biomed Pharmacother. 2018; 98:286-296.

14. Lin C, Wang Y, Wang Y, et al. Transcriptional and posttranscriptional regulation of HOXA13 by lncRNA HOTTIP facilitates tumorigenesis and metastasis in esophageal squamous carcinoma cells. Oncogene. 2017;36(38):5392-5406

15. Zhang H, Zhao L, Wang YX, Xi M, Liu SL, Luo LL. Long non-coding RNA HOTTIP is correlated with progression and prognosis in tongue squamous cell carcinoma. Tumour Biol. 2015;36(11):8805-8809.

16. Ait-Oudhia S, Mager DE. Array of translational systems pharmacodynamic models of anti-cancer drugs. J Pharmacokinet Pharmacodyn. 2016;43(6):549-565.

17. Deng HP, Chen L, Fan T, Zhang B, Xu Y, Geng Q. Long non-coding RNA HOTTIP promotes tumor growth and inhibits cell apoptosis in lung cancer. Cell Mol Biol. 2015;61(4):34-40.

18. Chen X, Han H, Li Y, Zhang Q, Mo K, Chen S. Upregulation of long noncoding RNA HOTTIP promotes metastasis of esophageal squamous cell carcinoma via induction of EMT. Oncotarget. 2016;7(51): 84480-84485.

19. Izdebska M, Zielińska W, Grzanka D, Gagat M. The Role of Actin Dynamics and Actin-Binding Proteins Expression in Epithelial-toMesenchymal Transition and Its Association with Cancer Progression and Evaluation of Possible Therapeutic Targets. Biomed Res Int 2018;2018:4578373-13.
20. Yang YK, Ogando CR, Wang See C, Chang TY, Barabino GA. Changes in phenotype and differentiation potential of human mesenchymal stem cells aging in vitro. Stem Cell Res Ther. 2018;9(1):131.

21. Stepp MW, Doll MA, Carlisle SM, States JC, Hein DW. Genetic and small molecule inhibition of arylamine $\mathrm{N}$-acetyltransferase 1 reduces anchorage-independent growth in human breast cancer cell line MDAMB-231. Mol Carcinog. 2018;57(4):549-558.

22. Zhang GJ, Song W, Song Y. Overexpression of HOTTIP promotes proliferation and drug resistance of lung adenocarcinoma by regulating AKT signaling pathway. Eur Rev Med Pharmacol Sci. 2017; 21(24):5683-5690.

23. Yang B, Gao G, Wang Z, et al. Long non-coding RNA HOTTIP promotes prostate cancer cells proliferation and migration by sponging miR-216a-5p. Biosci Rep. 2018:BSR20180566.

24. Sánchez I, Dynlacht BD. New insights into cyclins, CDKs, and cell cycle control. Semin Cell Dev Biol. 2005;16(3):311-321.

25. Li Z, Zhao L, Wang Q. Overexpression of long non-coding RNA HOTTIP increases chemoresistance of osteosarcoma cell by activating the Wnt/ $\beta$-catenin pathway. Am J Transl Res. 2016;8(5):2385-2393.

26. Zhang SR, Yang JK, Xie JK, Zhao LC. Long noncoding RNA HOTTIP contributes to the progression of prostate cancer by regulating HOXA13. Cell Mol Biol (Noisy-le-grand). 2016;62(3):84-88.

27. Xu LM, Chen L, Li F, et al. Over-expression of the long non-coding RNA HOTTIP inhibits glioma cell growth by BRE. J Exp Clin Cancer Res. 2016;35(1):162.

28. Gao W, Wu XL, Li DZ, Liu HD. HOTTIP participates in mammary cancer by promoting cell proliferation via PI3K/AKT pathway. Eur Rev Med Pharmacol Sci. 2018;22(13):4181-4187.

29. Guan Q, Zhang Q, Zhang C, Liu Q, Ren QL. HOTTIP regulates progression of endometrial cancer via activating PI3K/AKT pathway. Eur Rev Med Pharmacol Sci. 2018;22(12):3727-3733.

30. Villanova L, Careccia S, De Maria R, Fiori ME. Micro-Economics of Apoptosis in Cancer: ncRNAs Modulation of BCL-2 Family Members. Int J Mol Sci. 2018;19(4):958.

31. Sun Y, Hu B, Wang Q, et al. Long non-coding RNA HOTTIP promotes BCL-2 expression and induces chemoresistance in small cell lung cancer by sponging miR-216a. Cell Death Dis. 2018;9(2):85.

32. Ola MS, Nawaz M, Ahsan H. Role of Bcl-2 family proteins and caspases in the regulation of apoptosis. Mol Cell Biochem. 2011; 351(1-2):41-58.

33. Soldani C, Scovassi AI. Poly(ADP-ribose) polymerase-1 cleavage during apoptosis: an update. Apoptosis. 2002;7(4):321-328.

34. Sun Y, Zeng C, Gan S, et al. LncRNA HOTTIP-Mediated HOXA11 Expression Promotes Cell Growth, Migration and Inhibits Cell Apoptosis in Breast Cancer. Int J Mol Sci. 2018;19(2):472.

35. Li F, Cao L, Hang D, Wang F, Wang Q. Long non-coding RNA HOTTIP is up-regulated and associated with poor prognosis in patients with osteosarcoma. Int J Clin Exp Pathol. 2015;8(9):11414-11420.

36. Wei SC, Yang J. Forcing through Tumor Metastasis: The Interplay between Tissue Rigidity and Epithelial-Mesenchymal Transition. Trends Cell Biol. 2016;26(2):111-120.

37. Lian Y, Ding J, Zhang Z, et al. The long noncoding RNA HOXA transcript at the distal tip promotes colorectal cancer growth partially via silencing of p21 expression. Tumour Biol. 2016;37(6):7431-7440. 


\section{Supplementary material}

A

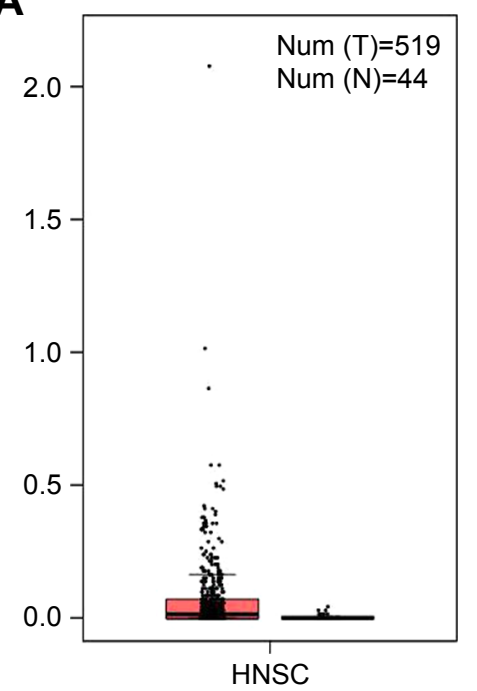

B

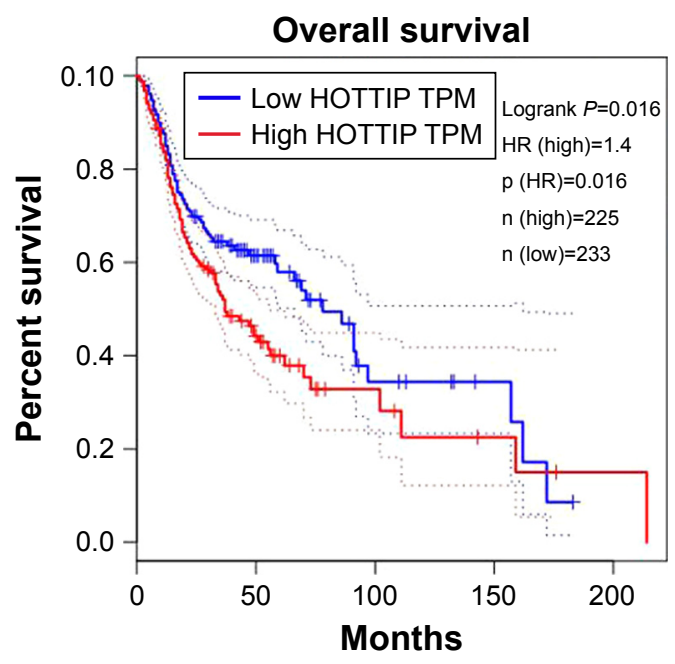

Figure SI HOTTIP was a prognostic factor for patients with HNSC.

Note: GEPIA was applied and the results were shown as (A) boxplot and (B) survival plot.

Abbreviations: HOTTIP, HOXA transcript at the distal tip; HNSC, head and neck squamous carcinoma; GEPIA, gene expression profiling interactive analysis.

\section{Publish your work in this journal}

OncoTargets and Therapy is an international, peer-reviewed, open access journal focusing on the pathological basis of all cancers, potential targets for therapy and treatment protocols employed to improve the management of cancer patients. The journal also focuses on the impact of management programs and new therapeutic agents and protocols on patient perspectives such as quality of life, adherence and satisfaction. The manuscript management system is completely online and includes a very quick and fair peer-review system, which is all easy to use. Visit http://www.dovepress.com/testimonials.php to read real quotes from published authors. 